\title{
Micromechanics based modeling of the Callovo-Oxfordian argillite mechanical behavior
}

\author{
Ariane Abou-Chakra Guéry ${ }^{1,2, a}$, Fabrice Cormery $^{1}$, Jian-Fu Shao ${ }^{1}$ \\ AND DJIMEDO KONDO ${ }^{1}$ \\ 1 Laboratory of Mechanics of Lille, UMR 8107, Cité scientifique, 59655 Villeneuve d'Ascq, France \\ 2 Agence Nationale pour la gestion des déchets radioactifs (ANDRA), 92296 Chatenay-Malabry, France
}

Received 15 March 2007, Accepted 7 June 2007

\begin{abstract}
The present study is devoted to the development and validation of a non-linear homogenization approach of the mechanical behavior of Callovo-Oxfordian argillites. The material is modelled as an heterogeneous one composed of an elastoplastic clay matrix and of linear elastic or elastic damage inclusions. The macroscopic constitutive law is obtained by adapting the Hill-type incremental method [1]. The approach consists in formulating the macroscopic tangent operator of the material from the non-linear local behavior of its phases. Due to the matrix/inclusion morphology of the microstructure of the argillites, a Mori-Tanaka scheme is considered for the localization step. The developed model is first compared to Finite-Elements calculations and then validated and applied for the prediction of the macroscopic stress-strain responses of argillites.
\end{abstract}

Key words: Geomaterials / non-linear homogenization / plasticity and damage / dilatancy / unilateral effects / experimental validation / rocks micromechanics

Résumé - Modélisation micro-macro du comportement élastoplastique endommageable de l'argilite du Callovo-oxfordien. Cette étude est consacrée au développement et à la validation d'une approche d'homogénéisation non-linéaire appliquée au comportement mécanique de l'argilite du Callovo-oxfordien. Le matériau est modélisé comme un composite à trois phases constitué d'une matrice élastoplastique et d'inclusions élastiques linéaires et élastiques endommageables. La loi constitutive macroscopique est obtenue à l'aide d'une adaptation de la méthode incrémentale de [1]. Cette approche aboutit à la construction de l'opérateur tangent macroscopique du matériau qui dépend du comportement local non-linéaire des phases. Compte tenu de la morphologie matrice/inclusion de la microstruture de l'argilite du Callovo-oxfordien, un schéma d'homogénéisation de type Mori-Tanaka est utilisé pour la résolution du problème de localisation. Le modèle ainsi développé est appliqué à la prédiction des réponses macroscopiques contrainte-déformation de l'argilite du Callovo-oxfordien sous différents trajets de chargement.

Mots clés : Géomatériaux / homogénéisation non-linéaire / plasticité et endommagement / dilatance / effets unilateraux / validation expérimentale / micromécanique des roches

\section{Introduction}

This study is performed in the general context of the project study of an underground disposal of radioactive waste, undertaken by the French National Radioactive Waste Management Agency (ANDRA). Its objective is to formulate a predictive constitutive model of the Callovo-Oxfordian argillite, a geological material chosen as one of possible barriers to radionuclides. Various

\footnotetext{
a Corresponding author:

ariane.guery@polytech-lille.fr
}

phenomenological models have been proposed in the past for this class of materials. For instance $[2,3]$ developed a phenomenological modelling approach which couples plasticity and damage at macroscopic scale. The plastic behavior is of non associated type with a particular emphasis on the plastic dilatancy (positive volumetric strains) while the damage component of the model allows to describe the deterioration of the materials properties. This model has been calibrated by using data from experiments on the Callovo-Oxfordian argillites and provided good predictions in term of the macroscopic stress-strain 
curve corresponding to various monotonic and cyclic compressive loading paths. Despite these predictions, these phenomenological models lack of link with a particular deformation mechanisms of the studied material regarding the strong heterogeneity of this one. Therefore it is interesting to develop for the Callovo-Oxfordian argillite a more physical modelling approach. The methodology followed in the present study consists then to develop a constitutive model of hard clays by using a non-linear homogenization approach. Various non-linear homogenization techniques have been developed in literature. Mention can be made of the so-called secant formulations by [4-6] for which the non-linear local behavior of each phase is linearized around an effective deformation.

Owing to the complexity of loading paths which are involved in the project of underground storage of radioactive waste, we have to adopt a rate type formulation instead of the above mentioned methods. For this purpose, we choose the incremental method of Hill [1] which consists, at each loading step, in determining the macroscopic tangent moduli from the local tangent behavior of the different constituents. The incremental approach has been recently considered by various authors for two phase composites; for instance [7] applied and discussed this method to metals plasticity with classical $J_{2}$ theory whereas [8] considered also a cyclic plasticity with a non-linear kinematic hardening. In these studies, a brief account of the interest of the incremental method in comparison with other methods such as the tangent approaches proposed by [9] and by [10]. In particular, it was demonstrated that a combination of the basic Hill's approach with an "isotropization procedure" leads to efficient predictions.

The objective of the present study is mainly to implement the incremental method for the modelling of a three phase material, namely the argillite which is constituted of a plastic clay matrix and elastic or damaged mineral inclusions. In addition to the coupling between plasticity and damage, the particularities of the study lie in the consideration of non associated and dilatant plasticity for the clay matrix and the extensive validation of the homogenized constitutive law by comparison with experimental data on various loading paths.

\section{Experimental observations on the Callovo-Oxfordian argillite behavior}

The material studied here is a sedimentary rock called Callovo-Oxfordian argillite, from the site where the underground research laboratory for nuclear waste disposal is operated by Andra. The Callovo-Oxfordian argillite is about $130 \mathrm{~m}$ thick. In this study, the rock samples come from three different depths. Although the depth difference is quite small (less than $30 \mathrm{~m}$ ), some variations in mineralogical compositions still exist (Fig. 1).

Mineralogical compositions, initial porosity and natural water content of samples were first investigated. Mineralogy was determined from results of X-ray diffractometry and calcimetry that showed a rather homogeneous

\begin{tabular}{|c|c|c|c|}
\hline $\begin{array}{c}\text { Depth (m) } \\
\text { Borehole EST104 }\end{array}$ & $\begin{array}{c}\text { Calcite content } \\
(\%)\end{array}$ & $\begin{array}{c}\text { Quartz content } \\
(\%)\end{array}$ & $\begin{array}{c}\text { Clays content } \\
(\%)\end{array}$ \\
\hline Depth 1:451.4-466.8 & $20-40$ & $20-30$ & $40-55$ \\
Depth 2 : 468.9-469.1 & $25-55$ & $20-30$ & $35-55$ \\
Depth 3:482.1-482.4 & $25-35$ & $15-20$ & $45-60$ \\
\hline
\end{tabular}

Fig. 1. Mineral compositions and basic proporties of CallovoOxfordian argillite.

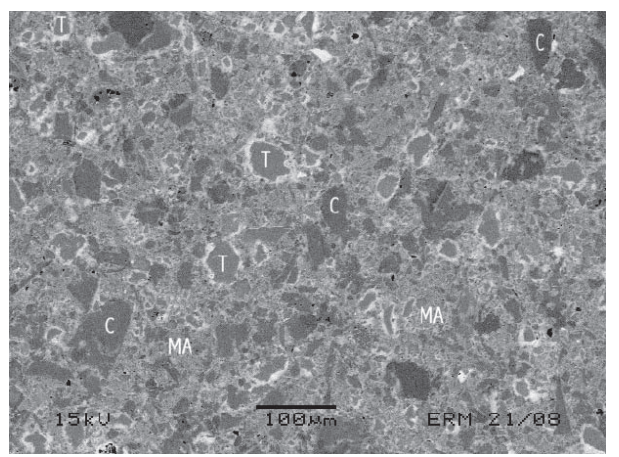

Fig. 2. Micrography of a typical Callovo-Oxfordian argillite structure: calcite grains (C), quartz grains (tectosilicates) (T) and clay matrix (MA).

composition of quartz ( $23 \%$ average), calcite ( $28 \%$ average) and clay minerals ( $45 \%$ average) together with subordinate feldspars, pyrite and iron oxides ( $5 \%$ average). The clay minerals composition is relatively constant at $65 \%$ I/S (illite-smectite interstratified minerals), 30\%-35\% illite and $0 \%-5 \%$ kaolinite and chlorite. At the microscopic level, quartz and large calcite grains are scattered in a fine matrix of clay minerals and calcite which acts to cement the larger grains (see Fig. 2). Mineral grains have principally a rounded shape and a dimension between 10 and $40 \mu \mathrm{m}$. The clay minerals are grouped in clusters of some microns large that can coat very well the grain form. Microstructural observations, [11] has shown the presence of clay particles in the layer of sheets, including quartz and calcite crystal grains. It was noted that the carbonated phase does not constitute a cement but is organized in grains spread in a clay matrix [2] remark in the same way that quartz and calcite grains are tied to the clay matrix. In Figure 2, we observe an organization of the clay minerals to a matrix in which we can find essentially calcite and quartz particles.

The previous analyses lead us to consider for the argillite a representative elementary volume (r.e.v.) composed of a three phase composite of inclusion/matrix type in which we discern the calcite and quartz phases supposed spherical and distributed in a clay matrix.

Other microstructural observations showed a lot of clay minerals extruded. This could be due to a relative slide movement between the slice inducing residual plastic deformations observed during triaxial compression tests $\left(\underline{\underline{\Sigma}}=\Sigma_{11} \underline{e_{1}} \otimes \underline{e_{1}}+\Sigma_{33}\left(\underline{e_{2}} \otimes \underline{e_{2}}+\underline{e_{3}} \otimes \underline{e_{3}}\right)\right)$ in the axial $\left(\overline{\bar{E}}_{11}\right)$ and lateral $\left(E_{33}\right)$ directions after unloading.

Relying on microscopic analysis, it is noted as well that mechanical properties of the argillite minerals are very contrasted (the quartz and calcite elasticity moduli 


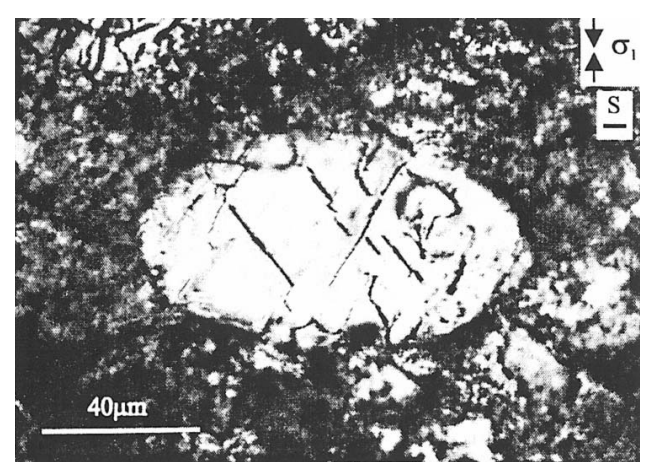

Fig. 3. Micrography of a calcite grain with transgranular fractures.

is around $100 \mathrm{GPa}$ whereas the clay one is around $10 \mathrm{GPa}$, ten less). This can induce high local deformations in the clay mass and weak one in the calcite and quartz grains. The phases heterogeneity also leads to shear stress concentration at the interfaces and can bring on microcracks by decohesion at the grains/matrix boundary or on transgranular fractures. The cracks inside the grains are principally visible in the calcite (Fig. 3) where it can be observed a network of microcracks with a quite isotropic distribution. For the sake of simplicity, we assume then an isotropic damage in this work. We will neglect as well the microcracking by decohesion to suppose that the only constituent who has an elastic damaged behavior is the calcite. This damage induced by microcracks growth can explain the degradation of the elastic stiffness observed during macroscopic tests on the argillite.

Therefore we will suppose an isotropic, linear and elastic behavior of the quartz grains, a damaged elastic behavior of the calcite grains with microcracks distributed in isotropic orientation and an elastoplastic behavior for the clay matrix. Further, influences of mineralogical composition on mechanical behavior of argillite have also been studied. The macroscopic elastic modulus increases with calcite content while it decreases with clay content. The Poisson's ratio is nearly insensitive to all the mineralogical constituents. Mineralogical compositions have also some effects on plastic deformation and induced damage.

\section{Incremental formulation of the homogenized constitutive law}

\subsection{Principle of the method}

As already stated, the Callovo-Oxfordian argillite can be represented by a three phases composite with distinct mechanical properties. This material is of a matrixinclusion morphology with phases randomly distributed, the calcite and quartz minerals being embedded in the clay matrix.

As classicaly, the r.v.e., named $V$, is subjected to an uniform strain rate boundary condition. $V_{r}$ and $f_{r}$, with $r=0,2$, are the volume of the different phases and the volume fraction of phase $r$, respectively. The compact notations $\bar{l}$ and $\bar{l}_{r}$ will be used to denote the average of a field $l$ in the entire r.v.e. $V$ and in each phase $V_{r}$, respectively

$$
\bar{l}=\langle l\rangle=\sum_{r=0}^{2} f_{r} \bar{l}_{r}, \bar{l}_{r}=\langle l\rangle_{r}=\frac{1}{\left|V_{r}\right|} \int_{V_{r}} l(\underline{x}) \mathrm{d} \underline{x}
$$

As already indicated, the methodology of the incremental method [1] consists to derive the overall tangent operator from the knowledge of the local behaviors. It requires a rate formulation of the mechanical behaviors of constituents:

$$
\underline{\underline{\dot{\sigma}}}(\underline{x})=\mathbb{L}(\underline{x}): \underline{\underline{\varepsilon}}(\underline{x})
$$

Since these local behaviors take the form of a linearized law given by tangent moduli, the classical Eshelby-based homogenization procedure is used for the resolution of the problem. For this purpose, a tangent localization tensor $\mathbb{A}$ which relates the local strain rate to the macroscopic strain rate has to be introduced:

$$
\underline{\underline{\varepsilon}}(\underline{x})=\mathbb{A}(\underline{x}): \underline{\underline{E}}
$$

By introducing the macroscopic tangent operator $\mathbb{L}^{\text {hom }}$, the macroscopic stress rate reads then:

$$
\underline{\underline{\dot{\Sigma}}}=\mathbb{L}^{\text {hom }}: \underline{\underline{\underline{E}}} \text { with } \mathbb{L}^{\text {hom }}=\langle\mathbb{L}: \mathbb{A}\rangle
$$

\subsection{Determination of the anisotropic tangent localization tensor}

For the implementation of the incremental method, we need an approximation of the tangent operator in each phase: at any point $\underline{x}$ of the phase $(r)^{1}$, the relation linking the strain rate to the stress rate can be approximated by:

$$
\forall \underline{x} \in(r), \underline{\underline{\dot{\sigma}}}(\underline{x})=\mathbb{L}_{r}: \underline{\underline{\varepsilon}}(\underline{x})
$$

It appears that $\mathbb{L}_{r}$ is evaluated for a reference state $\underline{\underline{\varepsilon}}_{r}$ classically chosen as the average of the strain field in the phase $(r)$. This way to treat the homogenization problem supposes implicitely that each phase have an uniform moduli while in the real material the strain field around and inside the inclusion is strongly heterogenous. The localization relation (3) reads then:

$$
\underline{\dot{\varepsilon}}_{r}=\mathbb{A}_{r}: \underline{\underline{E}}
$$

where $\mathbb{A}_{r}$ is the constant localization tensor in phase $r$ computed here by using the the Mori-Tanka scheme [12]. This scheme appears to be appropriate due to the matrix/inclusion morphology of the Callovo-Oxfordian argillite:

$$
\begin{aligned}
\mathbb{A}_{r}=\left[\mathbb{I}+\mathbb{P}_{I_{r}}^{0}:\left(\mathbb{L}_{r}-\mathbb{L}_{0}\right)\right]^{-1}: & \\
& {\left[\sum_{r} f_{r}\left[\mathbb{I}+\mathbb{P}_{I_{r}}^{0}:\left(\mathbb{L}_{r}-\mathbb{L}_{0}\right)\right]^{-1}\right]^{-1} }
\end{aligned}
$$

${ }^{1}$ (0) is the clay phase, $(1)$ is the calcite phase and (2) the quartz phase. 
$\mathbb{P}_{I_{r}}^{0}$ is the so-called Hill tensor which depends on the geometry of the inclusions $r$ (considered here as spheres) and on the tangent operator $\mathbb{L}_{0}$ associated to the clay matrix. Since the calcite and quartz grains have the same geometry, we will denote $\mathbb{P}_{I_{1}}^{0}=\mathbb{P}_{I_{2}}^{0}=\mathbb{P}_{I}^{0}$ with:

$$
\mathbb{P}_{I}^{0}=\mathbb{S}^{\mathrm{E}}\left(\mathbb{L}_{0}\right): \mathbb{L}_{0}^{-1}
$$

in which $\mathbb{S}^{\mathrm{E}}$ is the Eshelby tensor. Because of the anisotropy of the tangent operator $\mathbb{L}_{0}$, a numerical integration procedure is needed for the computation of the Hill tensor.

\section{Modelling of the local constituents behaviors}

\subsection{Elastoplastic behavior of the clay phase}

For the elastoplastic phase, we propose a non associated Drucker-Pager type model ([13]) with isotropic hardening. As classically, the free energy associated to the elastoplastic behavior is the sum of the elastic energy and the stored energy $W^{\gamma}\left(\gamma^{\mathrm{p}}\right)$ :

$$
W(\underline{\underline{\varepsilon}}, \beta)=\frac{1}{2}\left(\underline{\underline{\varepsilon}}^{-\underline{\varepsilon}^{\mathrm{p}}}\right): \mathbb{C}:\left(\underline{\underline{\varepsilon}}^{-\underline{\underline{\varepsilon}}^{\mathrm{p}}}\right)+W^{\gamma}\left(\gamma^{\mathrm{p}}\right)
$$

$\varepsilon^{\mathrm{p}}$ represents the plastic strain. An isotropic hardening, $\overline{\bar{d}}$ escribed by a scalar variable $\gamma^{\mathrm{p}}$, is assumed. $\mathbb{C}$ is the elastic stiffness tensor of the clay matrix which is assumed isotropic: $\mathbb{C}=3 k \mathbb{J}+2 \mu \mathbb{K}$. The positive scalars $k$ and $\mu$ are respectively the elastic bulk and shear moduli; $\mathbb{J}$ and $\mathbb{K}$ the spherical and deviatoric operators, respectively. $\mathbb{J}=$ $\frac{1}{3} \underline{\underline{1}} \otimes \underline{\underline{1}}$ and $\mathbb{K}=\mathbb{I}-\mathbb{J}$. The tensors $\underline{\underline{1}}$ and $\mathbb{I}$ are respectively the second and fourth-order symmetric identity tensor.

In order to take into account the pressure sensitivity (effect of the hydrostatic stress), a Drucker-Prager type plastic yield function is used: $f\left(F^{\mathrm{p}}, F^{\gamma}, \gamma^{\mathrm{p}}\right)=f\left(\underline{\underline{\sigma}}, \gamma^{\mathrm{p}}\right)=$ $q+\alpha^{\mathrm{p}}\left(\gamma^{\mathrm{p}}\right)\left(p-c_{\mathrm{p}}\right)$ where $p=\operatorname{tr}(\underline{\underline{\sigma}}) / 3$ and $q=\sqrt{\frac{3}{2} \underline{\underline{s}}: \underline{\underline{s}}} ;$ tensor $\underline{\underline{s}}$ is the stress deviator. In agreement with experimental observations, an exponential form is adopted: $\alpha^{\mathrm{p}}\left(\gamma^{\mathrm{p}}\right)=\alpha_{m}^{\mathrm{p}}-\left(\alpha_{m}^{\mathrm{p}}-\alpha_{0}^{\mathrm{p}}\right) e^{-b \gamma^{\mathrm{p}}}$.

To describe dilatancy effects of the matrix, we adopt the following form of the plastic potential: $g\left(\underline{\underline{\sigma}}, \gamma^{\mathrm{p}}\right)=q+$ $\beta^{\mathrm{p}}\left(\gamma^{\mathrm{p}}\right) p$ where $\beta^{\mathrm{p}}$ is the dilatancy parameter. By analogy with $\alpha\left(\gamma^{\mathrm{p}}\right)$, we adopt: $\beta^{\mathrm{p}}\left(\gamma^{\mathrm{p}}\right)=\beta_{m}^{\mathrm{p}}-\left(\beta_{m}^{\mathrm{p}}-\beta_{0}^{\mathrm{p}}\right) e^{-b^{\prime} \gamma^{\mathrm{p}}}$.

The rate form of the constitutive equations, obtained by time derivation of the stress tensor $\underline{\underline{\sigma}}$, takes the following form:

$$
\underline{\underline{\sigma}}=\mathbb{L}: \underline{\underline{\varepsilon}}
$$

where the tangent modulus $\mathbb{L}$ is computed by using the classical methodology in plasticity:

$$
\mathbb{L}=3 k_{1} \mathbb{J}+2 k_{2} \mathbb{K}-2 k_{3} \underline{\underline{n}} \otimes \underline{\underline{1}}-2 k_{4} \underline{\underline{1}} \otimes \underline{\underline{n}}-2 k_{5} \underline{\underline{n}} \otimes \underline{\underline{n}}
$$

The parameters $k_{i}, i=1 \ldots 5$ are given by:

$k_{1}=k\left(1-\frac{\alpha^{\mathrm{p}} \beta^{\mathrm{p}} k}{h}\right), k_{2}=\mu, k_{3}=\frac{\mu}{h} \sqrt{\frac{2}{3}} \alpha^{\mathrm{p}} k$,

$k_{4}=\frac{\mu}{h} \sqrt{\frac{2}{3}} \beta^{\mathrm{p}} k, k_{5}=\frac{6 \mu}{h}$.

The other quantities read: $\underline{\underline{n}}=\frac{\underline{\underline{s}}}{\sqrt{\underline{\underline{s}}: \underline{\underline{s}}}}$ and scalar

$h=\alpha^{\mathrm{p}} \beta^{\mathrm{p}} k+3 \mu-\left(p-c_{\mathrm{p}}\right) \frac{\mathrm{d} \alpha^{\mathrm{p}}}{\mathrm{d} \gamma^{\mathrm{p}}}$.

\subsection{Elastic unilateral damage behavior of the calcite phasis}

As classically, a quadratic form has been chosen for the thermodynamical potential (free energy) corresponding to the elastic damage process:

$$
W(\underline{\underline{\varepsilon}}, d)=\frac{1}{2} \underline{\underline{\varepsilon}}: \mathbb{C}(d): \underline{\underline{\varepsilon}}
$$

$d$ is a positive and increasing scalar variable which characterizes the damage state of the calcite grains. It is designed to take into account the evolving of microstructure and in particular the microcracks growth. Because of the unilateral effects induced by the opening/closing of microcracks, the stiffness tensor $\mathbb{C}$ depends on the state of existing microcracks in the material. By considering the mathematical condition on the potential $W([14,15])$ and with micromechanical considerations, it is shown that $\mathbb{C}$ must take the following form:

$$
\mathbb{C}(d)=\left\{\begin{array}{l}
3 K(d) \mathbb{J}+2 G(d) \mathbb{K} \text { if } \operatorname{tr}(\underline{\underline{\varepsilon}})>0 \\
3 K_{0}(d) \mathbb{J}+2 G(d) \mathbb{K} \text { if } \operatorname{tr}(\underline{\underline{\varepsilon}}) \leq 0
\end{array}\right.
$$

In order to provide a physical basis to the damage model, we have chosen for the expression of the bulk modulus and for the shear modulus $K(d)$ and $G(d)$ micromechanical results established by Ponte-Castañeda \& Willis [16] for microcracked media. These results have the interest of taking into account, not only the interactions between microcracks, but also their spatial distribution. For the yield function $f$ the following form has been adopted:

$$
f\left(F^{\mathrm{d}}, d\right)=F^{\mathrm{d}}-H(d)
$$

where $F^{\mathrm{d}}$ is the thermodynamical force associated to the damage variable $d$ and $H$ is a scalar strictly positive function:

$$
\left\{\begin{array}{l}
H(d)=H_{0}(1+\eta d) \\
\text { with } H_{0}>0 \text { and } \eta>0
\end{array}\right.
$$

We then deduce the evolution law of the elastic damage law:

$$
\underline{\underline{\dot{\sigma}}}=\mathbb{L}: \dot{\underline{\varepsilon}}
$$

with the tangent operator $\mathbb{L}$ given by the following expression:

$$
\mathbb{L}=3 k_{1} \mathbb{J}+2 k_{2} \mathbb{K}-2 k_{3}(\underline{\underline{1}} \otimes \underline{\underline{e}}+\underline{\underline{e}} \otimes \underline{\underline{1}})-2 k_{4} \underline{\underline{e}} \otimes \underline{\underline{e}}(16)
$$




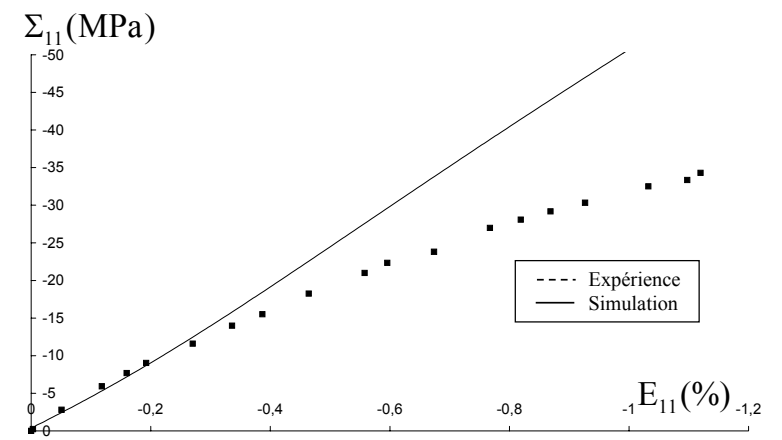

Fig. 4. Hard clay under uniaxial compression application of the incremental method to a compression test, prof: $466.8 \mathrm{~m}$, $f_{0}=51 \%, f_{1}=26 \%, f_{2}=23 \%$.

$$
\begin{aligned}
& k_{2}=G(d), k_{4}=\frac{2\left(G^{\prime}(d)\right)^{2}}{h}, \\
& \left\{\begin{array}{l}
k_{1}=\left(K(d)-\frac{\left(K^{\prime}(d) \operatorname{tr} \underline{\underline{\varepsilon}}\right)^{2}}{h}\right) \\
\quad \text { and } \quad k_{3}=\left(K(d)-\frac{G^{\prime}(d) K^{\prime}(d)}{h}\right) \text { if } \operatorname{tr}(\underline{\underline{\varepsilon}})>0 \\
k_{1}=K_{0} \text { and } k_{3}=0 \quad \text { if } \operatorname{tr}(\underline{\underline{\varepsilon}}) \leq 0
\end{array}\right. \\
& h=H_{0} \eta+K^{\prime \prime}(d) \operatorname{tr} \underline{\underline{\varepsilon 1}}+G^{\prime \prime}(d) \underline{\underline{e}}
\end{aligned}
$$

\section{Calibration and evaluations of the predictive capabilities of the micro-macro model}

\subsection{Local integration of the micromechanical model}

The practical implementation of the proposed micromacro incremental law requires the computation of the homogenized tangent operator in (4). We propose the following numerical scheme corresponding to a Representative Elementary Volume (r.e.v.) subjected to an uniform macroscopic strain rate $\underline{\underline{\underline{E}}}$. At a step $k$ tensor $\underline{\underline{\dot{\varepsilon}}}_{r}^{k}$ which represents the average strain rate in each phase $r$ is assumed to be known.

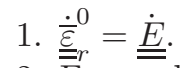

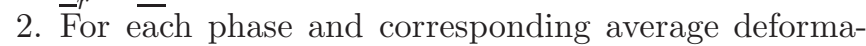
tion rate, the tangent operator $\mathbb{L}_{r}^{k}$ is computed.

3. We then deduce the Hill tensor $\mathbb{P}_{I_{r}^{0}}$ and the localisation operator $\mathbb{A}_{r}^{k}$ (Eq. (7)).

4. The average field of the local rate deformation is given

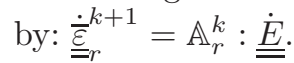

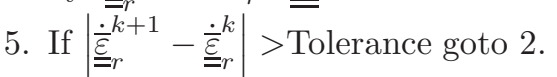

6. Else $\underline{\underline{\dot{\Sigma}}}=\sum_{r} f_{r} \mathbb{L}_{r}^{k}: \mathbb{A}_{r}^{k}: \underline{\underline{\underline{E}}}$.

\subsection{Identification of the model parameters}

The purpose of this section is to provide a first evaluation of the predictive capability of the proposed model by comparison with experimental data on the mechanical behavior of the hard clay. A first step is to determine the parameters of the model (6 elastic coefficients, 7 parameters involved in plastic law and 2 in the elastic damage law). The identification of the parameters in the local plastic and elastic damage model have been performed by calibration on uniaxial compression test at the depth $466.8 \mathrm{~m}$ (Fig. 4).

The matrix behavior is described by the following parameters: $E_{0}=3 \mathrm{GPa}, \nu_{0}=0.3, \alpha_{0}^{\mathrm{p}}=0.05, \alpha_{m}^{\mathrm{p}}=0.95$, $b=300, \beta_{0}^{\mathrm{p}}=-1.8, \beta_{m}^{\mathrm{p}}=0.3, b^{\prime}=400$ and $c_{\mathrm{p}}=14$. For the calcite one has: $E_{1}=95 \mathrm{GPa}, v_{1}=0.27, h=0.001$ and $\eta=150$. Finally, the elastic coefficients introduced for the quartz grains behavior are: $E_{2}=101 \mathrm{GPa}$ and $\nu_{2}=0.06$. In Figure 4, we present for an uniaxial compression test, a comparison between the model prediction and the experimental data. Unfortunately, it appears that the predicted response is too stiff comparatively to the experimental curve. This observation is similar to the one already reported by $([7,8])$ in the context of metals plasticity.

\subsection{Isotropization procedure and numerical predictions}

As suggested by [7] and [8] in the context of associated metals plasticity, a way to improve the model predictions consists in considering an isotropization procedure in which the Eshelby tensor is evaluated by using an isotropic approximation of the tangent moduli. In the case of a Drucker-Prager matrix, we have recourse to the general isotropization method described in [17] and applicable to any fourth order tensor:

$$
\mathbb{L}_{0}^{\text {iso }}=\left(\mathbb{J}:: \mathbb{L}_{0}\right) \mathbb{J}+\frac{1}{5}\left(\mathbb{K}:: \mathbb{L}_{0}\right) \mathbb{K}
$$

Replacing $\mathbb{L}_{0}$ by its expression (11) in (18), we obtain:

$$
\begin{array}{r}
\mathbb{L}_{0}^{\text {iso }}=3 k_{\mathrm{T}} \mathbb{J}+2 \mu_{\mathrm{T}} \mathbb{K} \\
k_{\mathrm{T}}=k\left(1-\frac{k \alpha^{\mathrm{p}} \beta^{\mathrm{p}}}{h}\right) \text { and } \mu_{\mathrm{T}}=\mu\left(1-\frac{3 \mu}{5 h}\right) \\
\text { with, } h=\alpha^{\mathrm{p}} \beta^{\mathrm{p}} k+3 \mu-\left(p-c_{\mathrm{p}}\right) \frac{d \alpha^{\mathrm{p}}}{d \gamma^{\mathrm{p}}}
\end{array}
$$

It can be noted that in the isotropic case as considered here, the Eshelby tensor is classicaly expressed as:

$$
\mathbb{S}^{\mathrm{E}}=\frac{3 k_{\mathrm{T}}}{3 k_{\mathrm{T}}+4 \mu_{\mathrm{T}}} \mathbb{J}+\frac{6}{5} \frac{k_{\mathrm{T}}+2 \mu_{\mathrm{T}}}{3 k_{\mathrm{T}}+4 \mu_{\mathrm{T}}} \mathbb{K}
$$

At the step (3) of the algorithm previously described, the Hill tensor is simply calculated from the following expression:

$$
\mathbb{P}_{I_{r}}^{0}=\mathbb{S}^{\mathrm{E}}\left(\mathbb{L}_{0}^{\text {iso }}\right): \mathbb{L}_{0}^{-1}, r=1,2
$$

Application of this new version of the model to the uniaxial compression test is shown in Figure $5 \mathrm{a}$ and proves that the isotropization procedure improves significant by the predictions of the micromechanical model. 


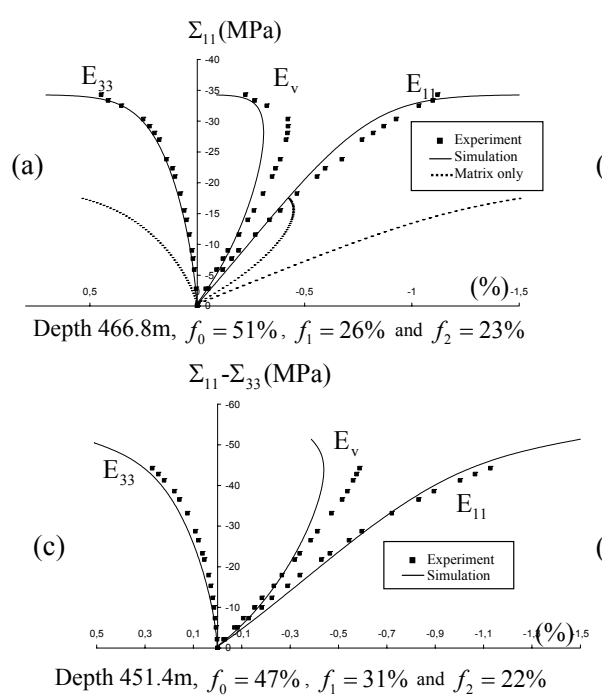

(b)
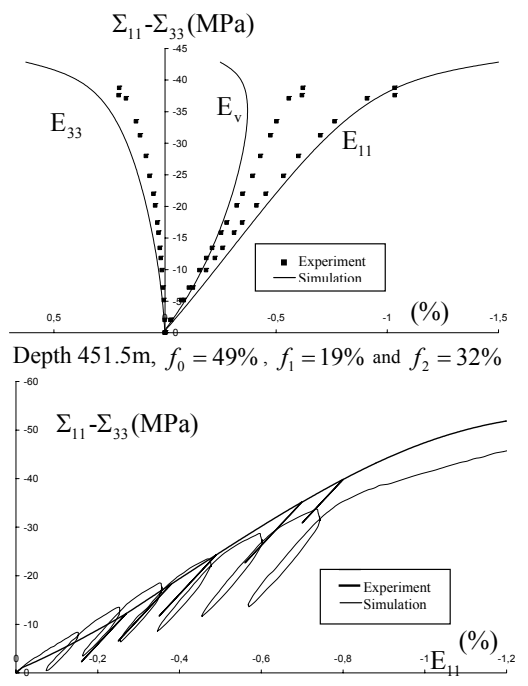

Depth $451.4 \mathrm{~m}, f_{0}=47 \%, f_{1}=31 \%$ and $f_{2}=22 \%$

Fig. 5. Depth 1. a) Simulation of an uniaxial compression test. b) Simulation of a triaxial compression test with 5 MPa confining pressure. c) Simulation of a triaxial compression test with $10 \mathrm{MPa}$ confining pressure. d) Simulation of a loading and unloading triaxial compression test with $10 \mathrm{MPa}$ confining pressure.
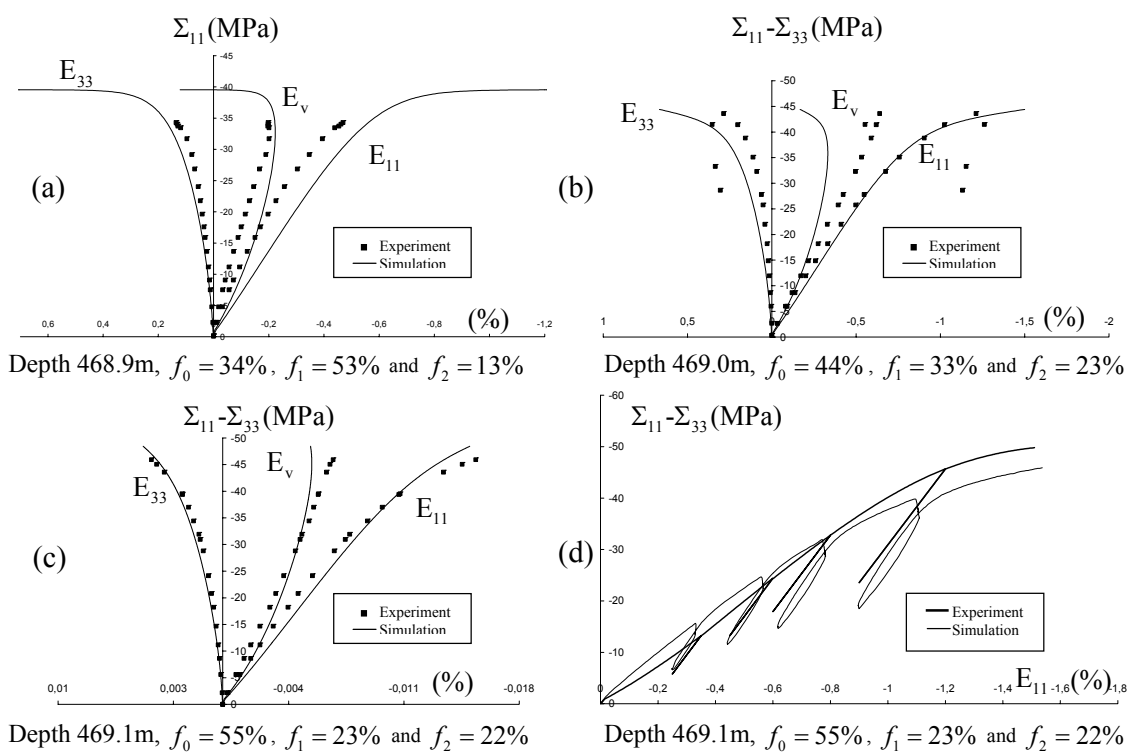

Fig. 6. Depth 2. a) Simulation of an uniaxial compression test. b) Simulation of a triaxial compression test with 5 MPa confining pressure. c) Simulation of a triaxial compression test with $10 \mathrm{MPa}$ confining pressure. d) Simulation of a loading and unloading triaxial compression test with $10 \mathrm{MPa}$ confining pressure.

\subsection{Experimental validations of the micromechanical model}

\subsubsection{Triaxial compression tests}

After the above calibration step, we propose to show the potentialities of the proposed model, keeping the same identified parameters on all tests (uniaxial and triaxial compression tests with 5 and $10 \mathrm{MPa}$ confinement pressure, proportional compression tests, lateral extension tests). The comparisons of the macroscopic stressstrain curves and the experimental data are presented in Figures 5-7 for triaxial compression tests. These comparisons indicate a good general agreement between the model predictions and experimental data including cyclic response of the materials. They provide a clear validation of the model for the study of the argillite. The simulations of unloading paths during the triaxial tests (Figs. 5, 6 and 7d) allow also to show the capability of the model to reproduce the deterioration of the macroscopic elastic properties of the material as observed in the experiments [2].

It is important to note that, without any complementary calibration, the model is able to reproduce tests 

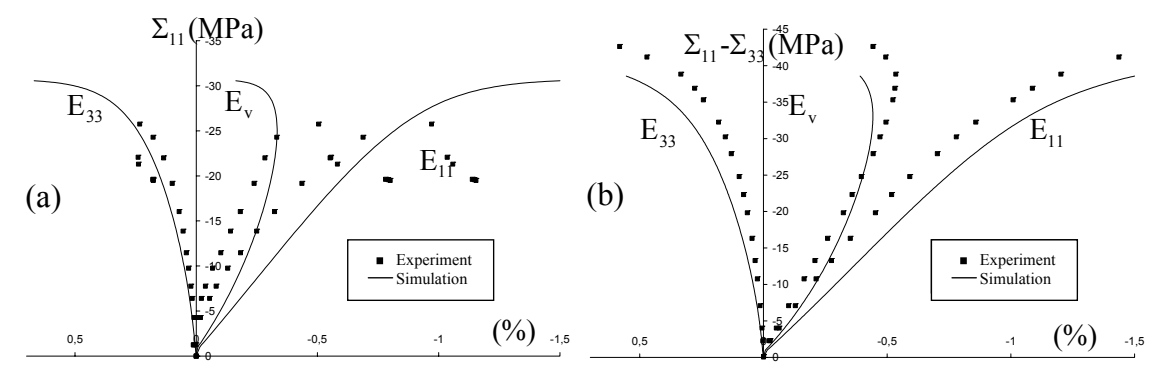

Depth $482.2 \mathrm{~m}, f_{0}=60 \%, f_{1}=26 \%$ and $f_{2}=14 \% \quad$ Depth $482.2 \mathrm{~m}, f_{0}=60 \%, f_{1}=26 \%$ and $f_{2}=14 \%$
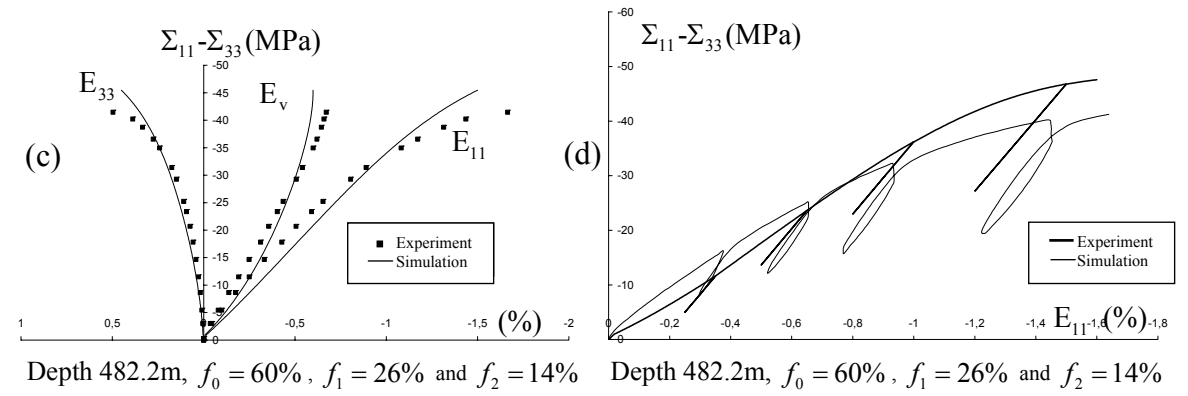

Fig. 7. Depth 3. a) Simulation of an uniaxial compression test. b) Simulation of a triaxial compression test with 5 MPa confining pressure. c) Simulation of a triaxial compression test with $10 \mathrm{MPa}$ confining pressure. d) Simulation of a loading and unloading triaxial compression test with $10 \mathrm{MPa}$ confining pressure.
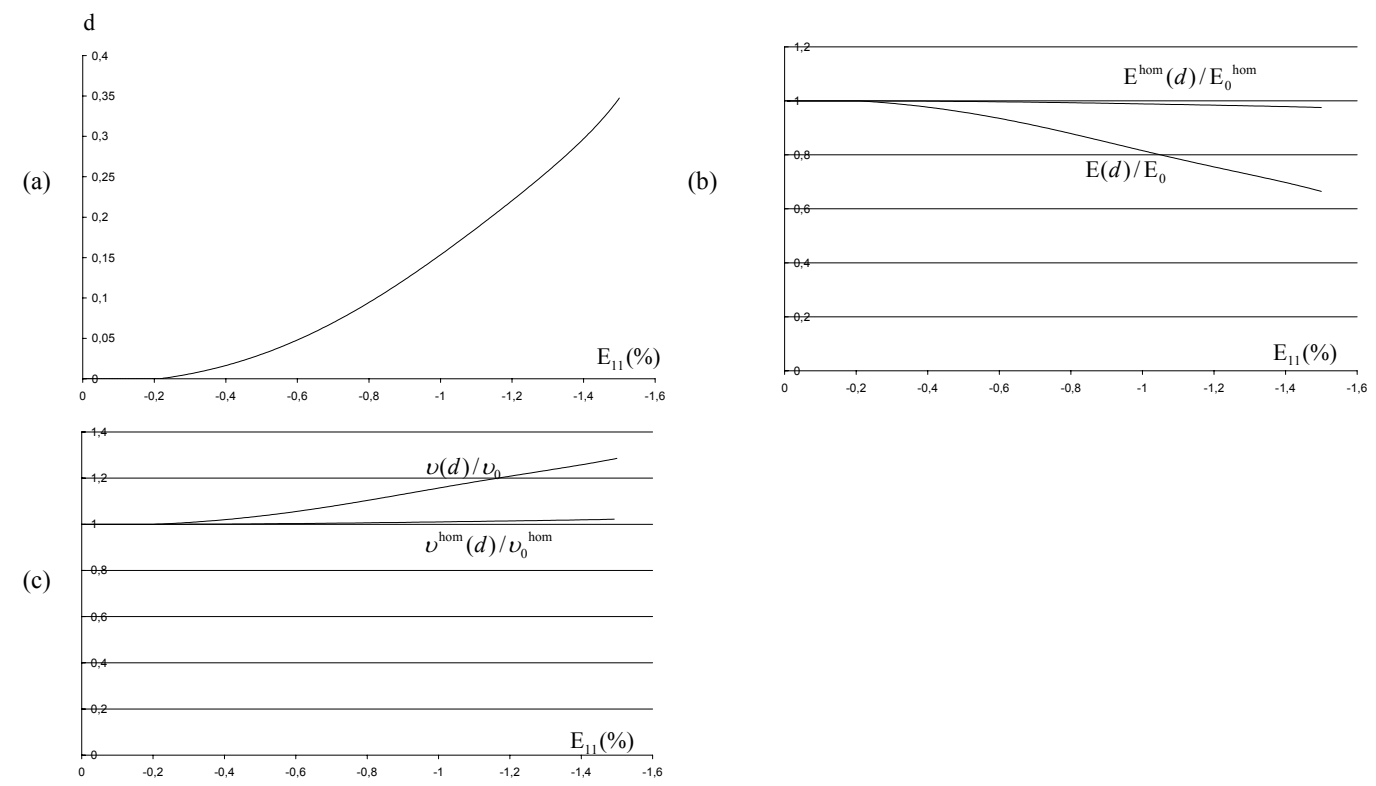

Fig. 8. Depth $451.4 \mathrm{~m} f_{0}=47 \%, f_{1}=31 \%$ and $f_{2}=22 \%$. Triaxial compression test with 10 MPa confining pressure. a) Variation of the local damage parameter with deviatoric stress. b) Variation of the local Young modulus ratio as a function of local lateral strain. c) Variation of the local Poisson's ratio as a function of local lateral strain.

corresponding to samples at different depths only by considering the appropriate (and measured) change in the mineral composition of the material. Another interesting advantage of the micromechanical model over purely phenomenological-based models is to provide predictions of the local fields at each macroscopic stress level. As an example, we report in Figure 8a the damage evolution in the calcite grains as function of the macroscopic axial strain. The effect of this local damage on the elasticity of the calcite grains, as well as on the macroscopic elastic moduli are shown in Figures $8 \mathrm{~b}$ and c. It is worthnoticing that the amplitude of the decrease of the elastic moduli at local and macroscopic scales are strongly different. A possible consequence of the local damage is that it can favour a strong increase of the overall permeability though the macroscopic mechanical 


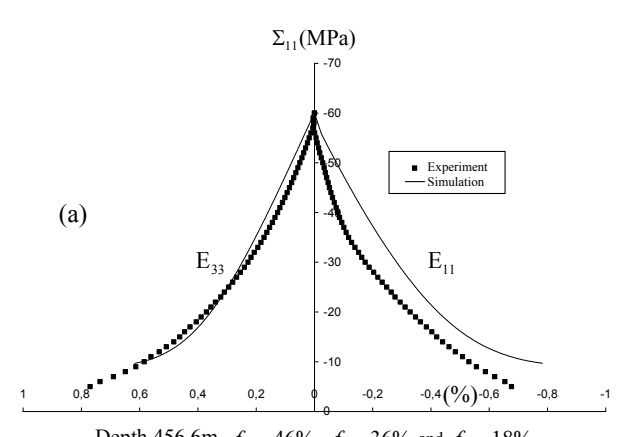

Depth $456.6 \mathrm{~m}, f_{0}=46 \%, f_{1}=36 \%$ and $f_{2}=18 \%$

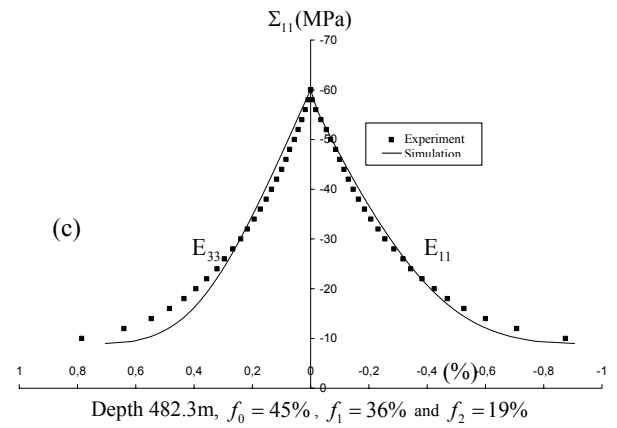

(b)

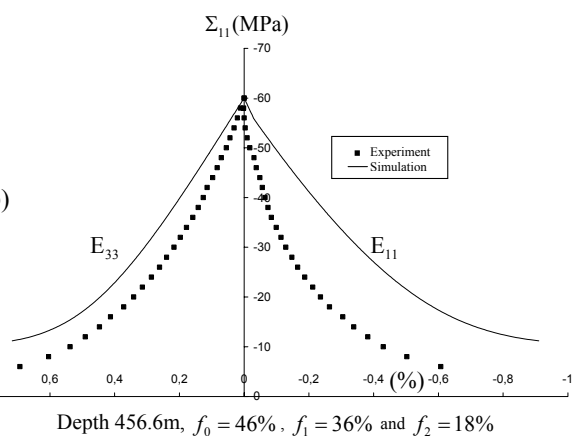

Depth $456.6 \mathrm{~m}, f_{0}=46 \%, f_{1}=36 \%$ and $f_{2}=18 \%$
(1) Depth 1

(a)

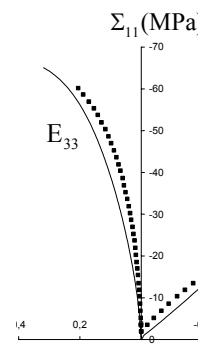

Depth $456.8 \mathrm{~m}, f_{0}=42 \%, f_{1}=40 \%$ and $f_{2}=18 \%$

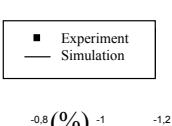

(2) Depth 2

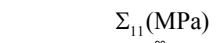

(a)
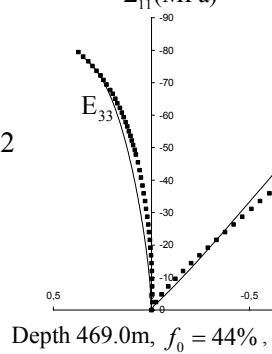

Depth $469.0 \mathrm{~m}, f_{0}=44 \%, f_{1}=33 \%$ and $f_{2}=23 \%$

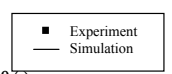

(b)

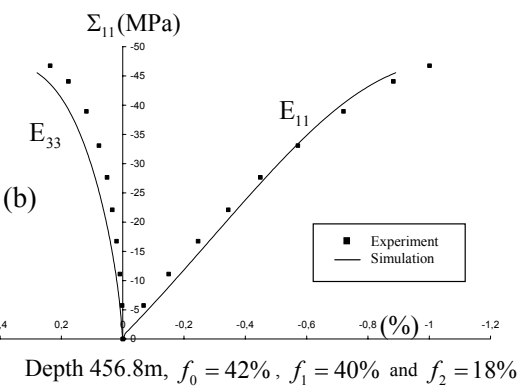

Depth $456.8 \mathrm{~m}, f_{0}=42 \%, f_{1}=40 \%$ and $f_{2}=18 \%$
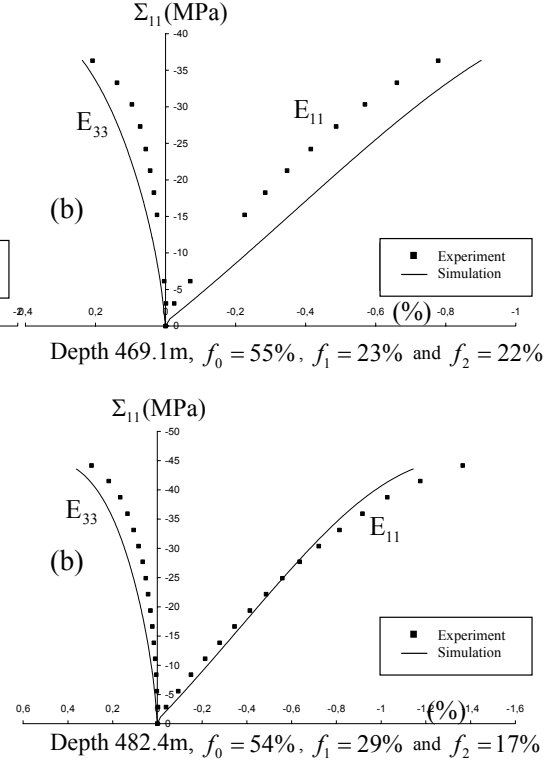

Fig. 10. Simulation of a proportional compression test with the stress ratio of $k=10$ for three ranges of depths. 
effect of damage is limited. Still, this is a crucial point which need to be investigated in future works (see for instance $[18,19])$.

\subsubsection{Proportional triaxial compression tests and lateral extension tests}

In order to provide complementary validations of the model, we investigate now very different loading paths, namely the proportional triaxial compression and the lateral extension test which are common in various geomechanical applications. In a lateral extension test, the sample is first submitted to a hydrostatic stress and then the confining pressure is reduced while the axial stress is kept at a constant value. In a proportional test, the axial stress and confining pressure are simultaneously increased with a constant ratio $k=\frac{\Sigma_{11}}{\Sigma_{33}}$. The results, shown in Figure 9 for proportional tests and in Figure 10 for lateral extension tests, demonstrate that the predictions of the model on this loading path are in agreement with experimental stress-strain curves. A good agreement is observed between the new theoretical results and experimental data. This proves again that the isotropization procedure improves the predictive capabilities of the micromechanical model.

\section{Conclusions}

The coupled elastoplastic damage behavior of a cohesive geomaterial, the Callovo-Oxfordian argillite, is investigated by the means of a non linear homogenization approach. The formulation of the model is carried out after a careful analysis of the microstructure and the deformation mechanisms of the studied class of materials. It is pointed out that the argillite can be described as a three phase medium whose constituents are the clay matrix, the quartz grains and the calcite grains. The clay matrix behaves as an elastoplastic material with possibility of a transition from plastic volumetric compressibility to dilatancy. In a first approximation and for the range of loadings considered, the quartz grains have been considered as linear elastic. Observation of intragranular microcracks in calcite grains has motivated the modelling of these grains by using a continuum damage mechanics approach.

Based on the various experimental data and observations, we have proposed a suitable model which takes advantage of the well known Hill-type incremental homogenization procedure, classically applied to plastic behavior of heterogeneous metals. The proposed micromechanical formulation of the plastic-damage coupled behavior enables the simulation of monotonous and cyclic loadings. A large validation of the model is provided, by confrontation with experimental data on various loading paths. More precisely, it is shown that, by considering a modified version of the original Hill method based on the use of an isotropization procedure of the local tangent moduli, we obtain model predictions in a very satisfactory agreement with experimental data. Moreover, the superiority of the micromechanical model over his phenomenological competitors is underlined by showing some predictions of local damage, local plastic deformations or of the effect of mineral composition of the material. Among others, current developments concern mainly the extension of the model to the poroplastic damage behavior of the argillite material when it is saturated by fluid under pressure as in [20] or in [21].

Acknowledgements. For its support, the French National Radioactive Waste Management Agency (Andra) is gratefully acknowledged. We would like to thank more particularly Doctor K. Su from Andra.

\section{References}

[1] R. Hill, Continuum micro-mechanics of elastoplastic polycrystals, J. Mech. Phys. Solids 13 (1965) 89-101

[2] A.-S. Chiarelli, J.-F. Shao, N. Hoteit, Modeling of elastoplastic damage behavior of a claystone, Int. J. Plasticity 19 (2003) 23-45

[3] N. Conil, I. Djeran-Maigre, R. Cabrillac, K. Su, Poroplastic damage model for claystones, Appl. Clay Sci. 26 (2004) 473-487

[4] M. Berveiller, A. Zaoui, An extension of the selfconsistent scheme to plasticity flowing polycrystals, J. Mech. Phys. Solids 26 (1979) 325-344

[5] P. Ponte-Castañeda, P. Suquet, Nonlinear composites, Adv. Appl. Mech. 34 (1998) 171-302

[6] G.-P. Tandon, G.-J. Weng, A theory of particle-reinforced plasticity, J. Appl. Mech. Trans. ASME 55 (1988) 126135

[7] J.-L. Chaboche, P. Kanouté, On the capabilities of meanfield approaches for the description of plasticity in metal matrix composites, Int. J. Plasticity 21 (2005) 1409-1434

[8] I. Doghri, A. Ouaar, Homogenization of two-phase elasto-plastic composite materials and structures: Study of tangent operators, cyclic plasticity and numerical algorithms, Int. J. Solids Structures 40 (2003) 1681-1712

[9] A. Molinari, G.-R. Canova, S. Ahzi, A self-consistent approach of the large deformation polycrystal viscoplasticity, Acta Metall. 35 (1987) 2983-2994

[10] R. Masson, M. Bornert, P. Suquet, A. Zaoui, An affine formulation for the prediction of the effective properties of nonlinear composites and polycrystals, J. Mech. Phys. Solids 48 (2000) 1203-1227

[11] R. Gasc, Couplages hydromécaniques dans les argilites de l'est et les siltites du Gard, Report ANDRA G3S B RP 0.G.3S., 99-002/A, 1999

[12] T. Mori, K. Tanaka, Average stress in a matrix and average elastic energy of materials with misfitting inclusions, Acta Metall. Mater. 42 (1973) 597-629

[13] D.-C. Drucker, W. Prager, Soil mechanics and plastic analysis or limit design, Quartely of Appl. Math. 10 (1952) 157-175

[14] A. Curnier, Q.-C. He, P. Zysset, Conewise linear elastic materials, J. Elasticity 37 (1995) 1-38 
[15] H. Welemane, F. Cormery, An alternative 3D model for damage induced anisotropy and unilateral effect in microcracked materials, J. Phys. 105 (2003) 329-336

[16] P. Ponte-Castañeda, J.-R. Willis, The effect of spatial distribution of effective behavior of composite materials and cracked media, J. Mech. Phys. Solids 43 (1995) 19191951

[17] M. Bornert, T. Bretheau, P. Gilormini, Homogénéisation en mécanique des matériaux 1, Matériaux aléatoires élastiques et milieux périodiques, Hermes Sciences Europe Ltd, 2001

[18] J.-F. Shao, H. Zhou, T. Chau, Coupling between anisotropic damage and permeability variation in brittle rocks. Int. J. for Numerical and Analytical Methods in Geomechanics 29 (2005) 1231-1247

[19] L. Dormieux, D. Kondo, Diffusive transport in disordered media, Application to the determination of the tortuosity and the permeability of cracked materials, Applied Micromechanics of Porous Media, L. Dormieux, F.-J. Ulm (eds.) CISM Courses and lectures 480 (2005) 83-106

[20] L. Dormieux, D. Kondo, F.-J. Ulm, Microporomechanics, Wiley, 2006

[21] J.-F. Shao, Y. Jia, D. Kondo, A.-S. Chiarelli, A coupled elastoplastic damage model for semi-brittle materials and extension to unsaturated conditions, Mechanics Materials 38 (2006) 218-232 